\section{SOI: $1.1 / \mathrm{TAS} \quad$ DOI: $10.15863 / \mathrm{TAS}$ International Scientific Journal Theoretical \& Applied Science}

p-ISSN: 2308-4944 (print) e-ISSN: 2409-0085 (online)

Year: $2018 \quad$ Issue: $06 \quad$ Volume: 62

Published: $26.06 .2018 \quad$ http://T-Science.org

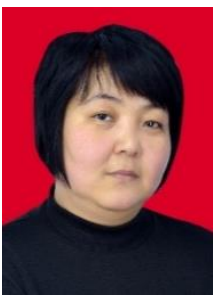

Nazgul Kurmanalievna Matikeeva Senior Lecturer of the Department of Economics and Taxes Faculty of Business and Management Osh State University, Kyrgyz Republic

SECTION 30. Geography. History. Oceanology. Meteorology.

\title{
THE HISTORICAL ASPECTS OF THE EMERGENCE OF NATURAL AND RESOURCE CONFLICTS IN THE MODERN FERGANA VALLEY
}

Abstract: This article examines the historical aspects of the emergence of natural and resource conflicts in the modern Fergana Valley. Based on the analysis of historical aspects, the main factors of formation and development of natural-resource conflicts in the Central Asian region, in particular in the Fergana region, have been identified.

Key words: history, society, ethnic groups, natural resource conflicts, national-territorial disengagement, primary and secondary factors of natural resource conflicts.

Language: Russian

Citation: Matikeeva NK (2018) THE HISTORICAL ASPECTS OF THE EMERGENCE OF NATURAL AND RESOURCE CONFLICTS IN THE MODERN FERGANA VALLEY. ISJ Theoretical \& Applied Science, 06 (62): 81-85.

Soi: http://s-o-i.org/1.1/TAS-06-62-18 Doi: crossef https://dx.doi.org/10.15863/TAS.2018.06.62.18

УДК: 913.1/913.8

\section{ИСТОРИЧЕСКИЕ АСПЕКТЫ ВОЗНИКНОВЕНИЯ ПРИРОДНО-РЕСУРСНЫХ КОНФЛИКТОВ В СОВРЕМЕННОЙ ФЕРГАНСКОЙ ДОЛИНЕ}

Аннотация: В данной статье рассматриваются исторические аспекты возникновения природноресурсных конфликтов в современной Ферганской долине. На основе анализа исторических аспектов, выявлены основные факторы формирования и развития природно-ресурсных конфликтов в Центральноазиатском регионе, в частности в Ферганской области.

Ключевые слова: история, общества, этнические группы, природно-ресурсные конфликты, национально - территориальное размежевание, первичные и вторичные факторы природно-ресурсных конфликтов.

\section{Introduction}

Территория Ферганской долины с XVIII века до вхождения Средней Азии в состав Российской Империи относилась к единому государственному образованию - Кокандскому ханству, являясь его центральной (ядерной) частью. Важной чертой политической организации ханства, как любого феодального государства, являлась достаточно широкая внутренняя автономия его территорий - городов и отдельных бекств и байств. Несмотря на этническую пестроту населения (в долине, помимо узбеков, кыргызов и таджиков проживали также кипчаки, каракалпаки, уйгуры, арабы, евреи, казахи и ряд других этнических групп), политические границы по национальному признаку здесь не проводились. Более того, значительную часть населения Кокандского ханства (и, соответственно, Ферганской долины) составляли сарты - оседлое тюркоязычное население, представляющее собой сложный синтез разнородных этнических элементов, объединенных общим типом хозяйства, одинаковым бытом, близкими говорами и единым самосознанием [1, 3-6]. По оценкам первой, проведенной русскими властями после присоединения ханства переписи населения, доля сартов в ханстве составляла около 26\%, при том, что доля основной этнической группы ханства кыргызов составляла немногим более 50\% [2]. Политическая целостность государства (что являлось типичным для Центральной Азии) основывалась не на этнической, а на территориальной и цивилизационной общности. 
Это выражалось, в частности, в отличиях в быту, языке и жизненных установках различных этнических групп, проживающих на территории долины (худжандских таджиков, ошских кыргызов), от представителей этих же этнических групп вне ее. Особенностью быта населения Ферганской долины являлось широкое распространение оседлого, в том числе, городского образа жизни. В долине было создано большое количество городов, многие из которых имели более чем тысячелетнюю историю. Распространение городского образа жизни в условиях полиэтнического общества способствовало этническому сближению населения долины, ассоциирование себя с этнической группой, рассматривавшийся на данной территории в качестве «городской», т. е. основного носителя городской культуры. Примечательной в этом отношении являлась распространенная еще в середине XIX века практика причисления себя к узбекам представителей других этнических групп долины при переселении в города[3, 175]. Другой этнической группой, немногочисленной (около $1 \%$ населения), но сплоченной, заметно отличающейся от остальных этносов долины по образу жизни (преобладал кочевой) и имевшей большое влияние на политическое устройство ханства, были кипчаки. Они относительно слабо смешивались с остальным населением долины, благодаря своей сплоченности и образу жизни представляли значительную вооруженную силу, влиявшую, в том числе и на политику ханства вплоть до смещения ханов. Этим они вызывали ненависть остального населения долины[4]. В то же время кипчаки могли рассматриваться как единственное в дороссийский период сообщество долины, организованное и выстраивающее свои цели, ориентируясь, преимущественно на этнические принципы. Однако и они не имели в пределах долины четко очерченной территории проживания. Еще одним фактором, обеспечивающим политическое единство населения Ферганской долины того периода была конфессиональная общность - подавляющую часть ее населения составляли мусульманесунниты [5, 194-211]. Нахождение в составе Кокандского ханства практически весь период его существования (с несколькими короткими перерывами) обеспечивало развитие всей территории долины в качестве единой экономико-географической и политикогеографической общности.

\section{Materials and Methods}

Присоединение Кокандского ханства в 1876 году к Российской империи существенно изменило геополитическое и геокультурное положение Ферганской долины. Из центрального региона самостоятельного периферийного (по меркам XIX века) государства, имевшего существенное политическое, экономическое и культурное влияние на окружающее пространство, долина превращается в периферийную территорию, управляющуюся смешанной администрацией колониального типа. Внешнее управление тормозит процессы саморегуляции этнополитической системы, сглаживает уровень административного влияния долины на окружающие территории. Однако и после присоединения последнего к Российской Империи, долина оставалась единым ядром административно-территориальной единицыФерганской области Туркестанского генералгубернаторства Российской Империи, включившей в себя современную узбекскую и кыргызскуютерриторию Большой Ферганской долины. Таджикская территория (Ходжентский уезд) была отнесена к Самаркандской области. Сохранял статус ведущего административного центра территории и Коканд, являвшийся исторически политическим центром территории. Тем не менее, в это время уже была заложена основа произошедшего в дальнейшем административного разделения пространства долины: территория области была подразделена на пять уездов (Ошский, Кокандский, Скобелевский, Андижанский и Наманганский), границы между которыми проходили по территории долины. Их центры: Андижан, Наманган, Коканд и Ош превратились из городских поселений с высоким уровнем автономии в рамках единого государства в административные центры, в подчинении которых находились значительные территории. Был создан и новый административный центр Скобелев (С 1876 по 1907 - Новый Маргилан, с 1924 года - Фергана), ставший впоследствии областным центром Ферганской области Узбекской ССР, с его строительством в долине начинается формирование городских агломераций современного типа. Тем не менее, после присоединения ханства к России, здесь сохраняется существовавший ранее принцип владения и управления основными ресурсами (земельными и водными), а также права собственности на них, при проведении административных границ этнический принцип не является ведущим, что позволяет довольно долго сохранить сложившийся территориальный принцип самоопределения и самосознания у населения долины.

Однако, наиболее значительные (по сути революционные) изменения в территориальную структуре расселения, административнотерриториальном делении, этнокультурных процессах и другие компонентах организации общества произошли на территории долины 
после революции 1917 года. Переход от монархической империи с большим количеством феодальных пережитков в общественной организации к государству нового типа (социалистическому, устроенному по принципу федерации) переформатированием сопровождался территориального устройства страны, прежде всего, ее национальных окраин. В основу территориальной организации СССР на уровне союзных республик был положен национальный принцип, нетипичный для Центральной Азии. Для реализации выделения административных единиц высшего порядка (республик) на территории Средней Азии, в том числе и в Ферганской долине было проведено национально-территориальное размежевание. В долине оно проходило в три этапа. На первом (1924-25 г. г.) территория долины была поделена между Узбекской ССР (с Таджикской АССР в ее составе) и Кара-Киргизской АССР в составе РСФСР. Вторым этапом национальнотерриториального размежевания в Ферганской долине стала передача Ходжентского округа из Узбекской ССР в подчинение вновь образованной Таджикской ССР. Третьим этапом стало повышение статуса Киргизской АССР (в этом статусе с 1926 года) в составе РСФСР до отдельной союзной республики в 1936 году и отнесение административных районов Ферганской долины, расположенных на ее территории в административное подчинение Джалал-Абадской и Ошской областей в 1939 году.

Результатом национально-территориального размежевания стали выделенные в общих чертах (практически не делимитированные) границы союзных республик в долине, которые имеют здесь весьма сложную конфигурацию (в том числе и с образованием анклавов), обусловленную особенностями расселения титульных наций среднеазиатских республик. Отсутствие четкой делимитации границы в условиях территории с выраженным дефицитом природных ресурсов способствовало при распаде единого государства формированию многочисленных очагов территориальных и ресурсных приграничных конфликтов. Ситуацию ухудшило и то, что в рамках единого государства (Советского Союза) жители разных республик в пределах долины пользовались общими источниками природных ресурсов и единой инфраструктурой их эксплуатации. Кроме того, национально-территориальное размежевание заложило фундамент глобального (в условиях Ферганской долины) природно-ресурсного конфликта, выходящего за рамки пограничных споров. Речь идет о водно-энергетической проблеме. Связан данный конфликт с тем, что основные источники водных ресурсов (истоки рек) располагаются на территории горных регионов Кыргызстана и Таджикистана, бедных ископаемым топливом, прежде всего, углеводородами, основные запасы которых сконцентрированы в узбекской части долины. В советский период были организованы поставки углеводородов из низовий долины в горные районы этих республик, кроме того, были созданы крупные ГЭС: Рогунская в Таджикистане и Токтогульская в Кыргызстане, работа которых снижала остроту энергетического дефицита, а водохранилища являлись частью системы водорегулирования в долине и бассейне Сырдарьи в целом. Однако, с распадом СССР, достаточно быстро распалась и система обеспечения узбекскими углеводородами Кыргызстана и Таджикистана, результатом чего стала необходимость задействования в холодный период мощностей ГЭС для выработки дополнительной электроэнергии. Это провоцировало зимние попуски из водохранилищ, что отрицательно сказалось на всей системе распределения воды в долине и породило острый межгосударственный спор о принципах водорегулирования в бассейне Сырдарьи.

Однако, проблемы, созданные национальнотерриториальным размежеванием в Ферганской долине заметно глубже и не ограничиваются только появлением границ, исторически не существовавших. Одной из проблем, порожденных этим политическим актом, стало грубое вмешательство государства в этническую структуру и этнические процессы в долине. Национально-территориальное размежевание в долине производилось между тремя титульными народами Средней Азии: узбеками, таджиками и кыргызами. Многие другие этнические группы в целях облегчения процесса размежевания принудительно относились к титульным нациям. Так, уже на начальном этапе национальнотерриториального размежевания к узбекам были отнесены все сарты[6, 53]. Позже к узбекам и, частично, к кыргызам были отнесены и кипчаки. Таким же образом к титульным нациям относили и другие близкие к ним малые этнические группы, проживавшие достаточно компактно. Поэтому к концу процесса национальнотерриториального размежевания существовавшие различия между сообществами представителей титульных наций, проживающими в долине и их соплеменниками вне ее заметно усилились. И это происходило на фоне осознания значимости этнической принадлежности основной массы членов того или иного местного сообщества для получения прав на определенную территорию и доступа к связанным с нею природным ресурсам. Это стало важным условием развития 
клановости, этнического местничества, которые подпитывались, с одной стороны, вновь возникшей необходимостью пересматривать права на те или иные территории в долине, исходя из своей этнической принадлежности, с другой стороны - заметными различиями в бытовом и социально-культурном плане с большинством представителей титульных наций «своих» республик, которые (различия) порождают с ними определенные противоречия.

Важным аспектом национальнотерриториального размежевания для долины стала смена вектора социально-культурного влияния. Утратив территориальную общность, а также, в результате административнотерриториальных преобразований и единый исторический административный центр(статус Коканда к 1930-м годам был понижен до районного центра в составе Ферганской области Узбекской (СР), территории долины, отнесенные к разным республикам, стали ориентироваться на внешние по отношению к долине социальнокультурные центры, прежде всего - столицы союзных республик. Это способствовало весьма быстрому размыву характерной для долины в начале XX века идентичности полиэтнического общества на основе территориальной и социально-бытовой близости и замена ее суррогатом из территориальной и этнической идентичности. Переориентирование социальнокультурного развития долины на внешние центры также ознаменовало собой окончательное превращение ее из политико-административного и социально-культурного центра регионального значения в региональную периферию с высокими рисками социальной деградации. Положение в советский период в определенной мере сглаживал высокий хозяйственный потенциал долины. В поздний советский и постсоветский период, когда востребованность хозяйственного потенциала долины существенно упала, социальная деградация в долине проявилась в полном объеме, в том числе и в форме большого числа конфликтов.

Важным административным фактором повышения конфликтогенности территории Ферганской долины явилась также крайняя неустойчивость границ административнотерриториальных образований внутри бывших союзных республик. Так, только в Кыргызской Республике границы Ошской области несколько раз изменялись: в нее включали Жалалабадскую область, потом выводили из ее состава, затем выводили из ее состава город Ош и Баткенскую область. Менялись и границы, а также административная принадлежность как районов, так и входящих в их состав административнотерриториальных образований

(c соответствующим изменением принадлежности и прав управления природными ресурсами и инфраструктурой). Такие изменения в условиях перманентного дефицита природных ресурсов породили ряд конфликтов (в частности пастбищные конфликты в Карасууйском районе), связанны с правами тех или иных общин на эксплуатацию определенных природных ресурсов.

Для последних десятилетий характерным для Ферганской долины демографическим процессом стало вымывание из этнического состава территорий наций, не составляющих на них большинства. Этот процесс весьма активно идет во всех государствах, относящихся к долине, но наиболее активен он в Узбекистане. В этническом составе населения районов и городов снижается доля, прежде всего, некоренных народов - русских, турок, татар и др., однако, идет и заметное снижение доли этносов, являющихся коренными для Ферганской долины, но не относящихся к титульной нации государства, к которому относится соответствующий район/город.

\section{Conclusion}

Природно-ресурсные конфликты на территории Ферганской долины по своему отношению к природным ресурсам и их задействованию в системе хозяйства территории можно подразделить на первичные, связанные с непосредственным использованием определенной группы природных ресурсов и вторичные, порождаемые поиском и использованием альтернативных ставшему дефицитным/недоступным ресурсов. Первичные и вторичные конфликты, в свою очередь, могут быть подразделены на следующие категории.

\section{Первичные:}

$\square$ связанные с борьбой за природный pecyрс, ставший дефицитным в результате истощения при непосредственном использовании. Особенностью конфликта является включение в противоборство за него как отдельных лиц, так и групп и организаций (вплоть до государств и международных структур), непосредственно эксплуатирующих данный природный pecypc. В условиях Ферганской долинытаким ресурсом является земля, пригодная для сельскохозяйственного использования. Географически они приурочены к наиболее густонаселенным территориям на которых дефицит основных ресурсов наиболее выражен;

$\square$ связанные с борьбой за ресурс, ставший дефицитным в результате изменения прав доступа к нему. Здесь в качестве конфликтующих сторон выступают преимущественно организации (реже - группы) уровня от местных сообществ до государств. В условиях Ферганской долины 
таким ресурсами являются водные, некоторые участки сельскохозяйственных земель (прежде всего - пастбища), лесные и минеральные (особенно - энергетические) ресурсы. Географически такие конфликты приурочены к приграничным территориям и в несколько меньшей мере - к территориям относительно недавно изменившим свою внутригосударственную административную принадлежность;

$\square$ связанные с борьбой за ресурс, теряющий качество из-за сопутствующей или альтернативной хозяйственной деятельности. В качестве конфликтующих сторон здесь, обычно, выступают группы и организации: местные сообщества, бизнес-структуры, государственные структуры, международные организации. В условиях Ферганской долины это конфликты, связанные со сведением лесов, промышленным и бытовым загрязнением почв и вод, зимними попусками воды на ГЭС.

Вторичные:

$\square$ связанные с поиском и использованием альтернативных ресурсов для существующего вида хозяйственной деятельности. По своей структуре такие конфликты смешанные - между личностью и организацией, группой и организацией, реже - личностью и группой или между группами и между организациями. В подавляющем большинстве случаев в конфликте участвуют члены одного местного или регионального сообщества, зачастую - органы государственной власти. В условиях долины одним из самых ярких примеров такого рода конфликтов является незаконная рубка лесов, используемых местными жителями в качестве источника топлива (дров).

Конфликт, сопряжённый с поисками альтернативного источника дохода/средств к существованию. По характеру сторон конфликта совпадает с конфликтом за альтернативный источник ресурсов. Отличается от него тем, что возникает на почве использования некоего peсурса в объемах или способами, нежелательными в местных условиях. Примером такого конфликта является борьба с рыбным браконьерством на Токтогульском водохранилище.

\section{References:}

1. Omurzakova T. (2016) Jetnicheskaja karta Kokandskogo hanstva (istorija i tendencii) // Austrian Journal of Humanities and Social Sciences, № 9-10, 2016, p. 3-6.

2. (1885) Proekt vsepoddannejshego otcheta General-Adjutanta K. P. fon Kaufmana po grazhdanskomu upravleniju i ustrojstvu v oblastjah Turkestanskogo generalgubernatorstva 7 nojabrja 1867-25 marta -1881 g. - SPb., 1885.

3. Arminij Vamberi. (2003) Puteshestvie po Srednej Azii. Mju: Vostochnaja literatura, 2003, p. 175 .

4. Shanijazov K.Sh. (1980) Kipchaki v uzbekskoj jetnicheskoj srede $\mathrm{v}$ dooktjabr'skij period (processy integracii) // Jetnicheskie processy u nacional'nyh grupp Srednej Azii i Kazahstana. M., 1980.

5. Olimov M. A., Olimova S. K. (1998) Hudzhand: mezhdu Ferganoj i Tadzhikistanom // Vestnik Evrazii, №. 1-2, 1998, p. 194-211.

6. Abashin S. N. (2008) Jetnograficheskoe znanie i nacional'noe stroitel'stvo v Srednej Azii: problema sartov v XIX - nachale XXI v / avtoreferat dis. doktora istoricheskih nauk: 07.00.07. - M.: In-t jetnologii i antropologii im. N.N. Mikluho-Maklaja RAN, 2008. - 53 p.

7. Komissina I. (1995) Integracionnye processy v Central'noj Azii // Novaja Evrazija: Otnoshenija Rossii so stranami blizhnego zarubezh'ja: sb. st. - M., 1995. - № 4.

8. Petrov G. (2010) Konflikt interesov mezhdu gidrojenergetikoj i irrigaciej v Central'noj Azii. Ego prichiny i puti preodolenija. // Central'naja Azija i Kavkaz. T.13, vypusk 3, 2010., p. 59-73.

9. Saidazimova G. (2000) Integracija v Central'noj Azii: realii, vyzovy, vozmozhnosti Central'naja Azija i Kavkaz. - 2000. - № 3(9). - p. 80-83.

10. Dabiri, Aliakbar. (1390) Ocenka mesta Central'noj Azii, zanimaemogo v geopoliticheskih teorijah. // Zhurn. «Central'naja Azija i Kavkaz» (na persidskom jazyke), №73, 1390 g. ot hidzhry, p. 61-84. 